\title{
CONCERNING THE INTERMEDIATE POINT IN THE MEAN VALUE THEOREM
}

\author{
DOREL I. DUCA AND OVIDIU T. POP
}

Abstract. If the function $f: I \rightarrow \mathbb{R}$ is differentiable on the interval $I \subseteq \mathbb{R}$, then for each $x, a \in I$, according to the mean value theorem, there exists a number $c(x)$ belonging to the open interval determined by $x$ and $a$, and there exists a real number $\theta(x) \in] 0,1[$ such that

$$
f(x)-f(a)=(x-a) f^{(1)}(c(x))
$$

and

$$
f(x)-f(a)=(x-a) f^{(1)}(a+(x-a) \theta(x)) .
$$

In this paper we shall study the differentiability of the functions $c$ and $\theta$ in a neighbourhood of a.

Mathematics subject classification (2000): 26A24.

Keywords and phrases: intermediate point, mean-value theorem.

\section{REFERENCES}

[1] Amann, Herbert And Escher, JoAchim, Analysis, Birkhauser Verlag, Basel-Boston-Berlin, I (1998), II (1999), III (2001)

[2] Andrica, D., Duca, D.I., Purdea, I. And Pop, I., Basic Mathematics (in Romanian), Studium Publishing House, Cluj-Napoca, 2004.

[3] Azagra, D., Gomez, J. And Jaramillo J.A., Rolle's Theorem and Negligibility of Points in Infinite Dimensional Banach Spaces, J. Math. Anal. Appl., 213 (1997), 487-495.

[4] Bartle, R.G. AND Sherbert, D.R., Introduction to Real Analysis, 3rd., J. Wiley, New York, 2000.

[5] Boggio, T., Sur une proposition de M. Рompeiu, Mathematica, 23 (1947-1948), 101-102.

[6] DucA, D.I., A Note on the Mean Value Theorem, Didactica Matematicii, 19 (2002), 91-102. (in Romanian)

[7] Duca, D.I. And DucA, E., Problems in Calculus, Editura GIL Educational, Zalău, 1999. (in Romanian)

[8] DuCA, D.I. And Pop, O., On the Intermediate Point in Cauchy's Mean Value Theorem, Math. Inequal. Appl., 9, 3 (2006), 375-389.

[9] Duca, D.I. And Pop, O.T., Properties of the Intermediate Point in the Mean Value Theorem, Didactica Matematicii, 21 (2003), 81-88. (in Romanian)

[10] Folland, G.B., Real Analysis, J. Wiley, New York, 1999.

[11] Furi, M. And Martelli, M., On the Mean Value Theorem, Inequality and Inclusion, Amer. Math. Monthly, 98, 9 (1991), 840-846.

[12] Grandshteyn, I.S. And Ryzhik, I.M., Table of Integrals, Series and Products, Academic Press, NY, 1980.

[13] IVAn, M., A Note on a Pompeiu Type Theorem, The $5^{\text {th }}$ Romanian-German Seminar on Approximation Theory and its Applications, Sibiu, 2002, pp. 129-134.

[14] Lieb, Elliott H. And Loss, Michael, Analysis, American Mathematical Society, 1997.

[15] LupAş, A., On the Mean Value Theorem, Revista matematica a elevilor din Timişoara, XIV, 2 (1983), 6-13. (in Romanian) 
[16] Pă VăLOIU, I., Solvind Equations by Interpolation, Editura Dacia, Cluj-Napoca, 1981. (in Romanian)

[17] Penot, J.P., Mean-Value Theorem with Small Subdifferentials, J. of Optim. Theory and Appl., 94, 1 (1997), 209-221.

[18] Pompeiu, D., Sur la théorème des accroissements finis, Ann. Scient. Univ. Jassy, 15 (1928/1929), $335-337$.

[19] Pompeiu, D., Sur une proposition analogue au théorème des accroissements finis, Mathematica, 22 (1946), 143-146.

[20] Rudin, W., Real and Complex Analysis, third edition, McGraw Hill, New York, 1987.

[21] Schechter, E., Handbook of Analysis and its Foundations, Academic Press, San Diego, 1997.

[22] Tchakaloff, I., Sur la théorème des accroissements finis, C. R. Acad. Sci. Paris, 192 (1931), 32-35.

[23] Turowicz, B.A., Sur les derivées d'ordre superieur d'une fonction inverse, Colloq. Math., (1959), 83-87.

[24] WACHNICKI, E., Une variante du théorème de Cauchy de la valeur moyenne, Demonstratio Math., 33, 4 (2000), 737-740. 